VNU Journal of Science: Legal Studies Journal homepage: https://js.vnu.edu.vn/LS

\title{
Review Article \\ Legal institution to ensure human rights, civil rights in Viet Nam Library Law 2019
}

\author{
Le Tung Son* \\ Ministry of Culture, Sports and Tourism, 51 Ngo Quyen, Hoan Kiem Ha Noi \\ Received 09 July 2020 \\ Revised 11 September 2020; Accepted 26 September 2020
}

\begin{abstract}
Abstracts: Library Law No. 46/2019 / QH14 passed by the National Assembly of the Socialist Republic of Vietnam on November 21, 2019, effective July 1st, 2020, has important implications for the completion of legal regulations on ensuring human rights and civil rights which is stipulated by the Constitution with the basic rights: the right to access information and the right to access and enjoy cultural values, to participate in cultural life and to use of cultural facilities. The study focuses on overview, analysis and identification of legal institution on ensuring human rights and civil rights in the Library Law, then recommends measures for the Law to be implemented in the coming time.
\end{abstract}

Keywords: Human rights, civil rights, library law, library activities.

\footnotetext{
* Corresponding author.

E-mail address: tungson.hlu@gmail.com

https://doi.org/10.25073/2588-1167/vnuls.4309
} 


\title{
Chế định pháp luật về bảo đảm quyền con người, quyền công dân trong Luật Thư viện 2019
}

\author{
Lê Tùng Sơn* \\ Bộ Văn hóa, Thể thao và Du lịch, 51 Ngô Quyền, Hoàn Kiếm, Hà Nội \\ Nhận ngày 09 tháng 7 năm 2020 \\ Chỉnh sửa ngày 11 tháng 9 năm 2020; Chấp nhận đăng ngày 26 tháng 9 năm 2020
}

\begin{abstract}
Tóm tắt: Luật Thư viện số 46/2019/QH14 được Quốc hội nước cộng hòa xã hội chủ nghĩa Việt Nam thông qua ngày 21 tháng 11 năm 2019, có hiệu lực kể từ ngày 01 tháng 7 năm 2020 mang ý nghĩa quan trọng trong việc hoàn thiện các chế định pháp luật về bảo đảm quyền con người, quyền công dân được Hiến pháp quy định với các quyền cơ bản đó là: quyền tiếp cận thông tin và quyền tiếp cận và hưởng thụ các giá trị văn hóa, tham gia vào đời sống văn hóa và sử dụng các cơ sở văn hóa. Nghiên cứu tập trung tổng quan, phân tích và nhận diện các chế định pháp luật về bảo đảm quyền con người, quyền công dân trong Luật Thư viện từ đó khuyến nghị các biện pháp để Luật được thực thi trong thời gian tới.
\end{abstract}

Từ khóa: Quyền con người, quyền công dân, Luật Thư viện, hoạt động thư viện.

\section{Dẫn nhập}

Ngày 21 tháng 11 năm 2019, Quốc hội nước cộng hòa xã hội chủ nghĩa Việt Nam đã thông qua Luật Thư viện số 46/2019/QH14, có hiệu lực kể từ ngày 01 tháng 7 năm 2020, sự kiện này không chỉ đánh dấu một bước phát triển mới đối với sự nghiệp thư viện tại Việt Nam, mà còn mang một ý nghĩa hết sức quan trọng trong việc hoàn thiện các chế định pháp luật về quyền con người, quyền của công dân đã được Hiến định đó là quyền tiếp cận thông tin quy định tại Điều 25 của Hiến pháp, quyền hưởng thụ và tiếp cận các giá trị văn hóa, tham gia vào đời sống văn hóa, sử dụng các cơ sở văn hóa quy định tại Điều 41 của Hiến pháp. Từ đó, người dân có thêm nhiều cơ hội được tiếp cận thông tin, hưởng thụ, tiếp cận với các giá trị văn hóa thông qua hoạt động thư viện, người dân trở thành chủ thể chính làm nên những giá trị cơ bản của hoạt động thư viện, là trung tâm

\footnotetext{
* Tác giả liên hệ.

Địa chỉ email: tungson.hlu@gmail.com

https://doi.org/10.25073/2588-1167/vnuls.4293
}

trong hoạt động của thư viện, tạo động lực cho việc học tập suốt đời, phát triển kỹ năng thông tin, góp phần phát triển văn hóa, con người Việt Nam đáp ứng nhu cầu phát triển bền vững đất nước. Gắn với các quyền cơ bản này đó là nghĩa vụ của Nhà nước trong việc bảo đảm thực thi thông qua các quy định có liên quan đến nâng cao chất lượng, phát triển sự nghiệp thư viện và các quy định khuyến khích tổ chức cá nhân tham gia thành lập và hoạt động thư viện.

Trong nghiên cứu này, trên cơ sở phân tích các quy định của Luật Thư viện, Tác giả đưa ra những nhận diện và đánh giá những chế định của pháp luật về quyền con người, quyền của công dân và những biện pháp để bảo đảm thực thi những quyền này, nghiên cứu này trả lời cho câu hỏi: Chế định pháp luật về bảo đảm quyền con người, quyền của công dân được đề cập trong Luật Thư viện bao gồm những nội dung gì? được bảo đảm thực thi như thế nào? Trên cơ sở đó, Nghiên cứu đề xuất một số giải pháp nhằm tăng cường việc thực thi pháp luật về thư viện, để phát huy vai trò của thư viện trong việc bảo đảm thực thi các quyền cơ bản của con người và của công dân. 


\section{Cơ sở lí luận về bảo đảm quyền con người, quyền công dân trong lĩnh vực thư viện}

\subsection{Quyền con người, quyền công dân}

Quyền con người, quyền công dân là những chế định pháp luật quan trọng được ghi nhận trong Hiến pháp và các đạo luật của một quốc gia. Tư tưởng về quyền con người được hình thành từ những nền văn minh cổ đại, nó xuất phát từ các quyền thiêng liêng, vốn có của con người và không do chủ thể nào ban phát [1]. Trên bình diện quốc tế, Quyền con người, quyền công dân được ghi nhận trong nhiều văn kiện quan trọng như công ước quốc tế về loại trừ các hình thức phân biệt chủng tộc năm 1965, Công ước quốc tế về các quyền dân sự, chính trị năm 1966, Công ước quốc tế về các quyền kinh tế, xã hội và văn hóa năm 1966, công ước quốc tế về xóa bỏ mọi hình thức phân biệt đối xử với phụ nữ năm 1979, Công ước về quyền trẻ em năm 1989... Ở Việt Nam, các quyền cơ bản này được ghi nhận trong Hiến pháp các năm 1946, 1959, 1980, 1992 và 2013. Có thể nhận diện nội hàm của 02 chế định pháp luật quan trọng này như sau:

a) Quyền con người

Quyền con người (Human Rights) là một trong những động lực của sự ra đời và cũng là mục tiêu mà những bản Hiến pháp của mỗi quốc gia hướng tới. Có nhiều hướng tiếp cận khác nhau khi đưa ra định nghĩa về quyền con người. Theo tổng hợp từ một tài liệu của Liên hợp quốc, đến nay, có đến gần 50 định nghĩa về quyền con người được đưa ra [2].

Trên bình diện quốc tế, Văn phòng Cao ủy Liên hợp quốc về quyền con người đưa ra định nghĩa: quyền con người là nhũng bảo đảm pháp lý toàn cầu, có tác dụng bảo vệ các cá nhân và các nhóm chống lại những hành động hoạc sư bỏ mặt mà làm tổn hại đến nhân phẩm, nhũng sư được phép và tụ do co bản của con người [3].

Ở Việt Nam, trong công trình nghiên cứu về Quyền con người trong thế giới hiện đại, Phạm Khiêm Ích, Hoàng Văn Hảo đã đưa ra định nghĩa: đó là những khả năng hành động một cách có ý thức, tránh, từ chối hoặc yêu cầu giành lấy những cái gì đó, nhất là tự vệ [4,tr19] . Một số công trình của các học giả khác nhận diện đó là những nhu cầu, lợi ích tự nhiên, vốn có của con người được ghi nhận và bảo vệ trong pháp luật quốc gia và các thỏa thuận pháp lý quốc tế [4].

Trong từ điển Luật học, quyền con người được định nghĩa là quyền của thành viên trong xã hội loài người - quyền của tất cả mọi người. Đó là nhân phẩm, nhu cẩu, lợi ích và năng lực của con người được thể chế hóa (ghi nhận) trong pháp luật quốc tế và pháp luật quốc gia [5].

b) Quyền công dân

Thuật ngữ "công dân" (citizen), theo Từ điển Merriam Webster's Collegiate Dictionary là một thành viên của một nhà nước mà người đó có nghĩa vụ trung thành và được hưởng sự bảo vệ. Quyền công dân (Citizen Rights) có thể hiểu là những lợi ích pháp lý được nhà nước thừa nhận và bảo vệ cho người có quốc tịch của nước mình.

Theo từ điển Luật học, quyền công dân là khả năng tự do lựa chọn hành vi của công dân mà nhà nước phải bảo đảm khi công dân yêu cầu. Quyền của công dân liên quan đến nghĩa vụ tương ứng của Nhà nước phải bảo đảm các điều kiện cần thiết cho công dân thực hiện các quyền đã được pháp luật quy định [6, 648-649]. Ngoài ra quyền của công dân có thể được hiểu là những gì được hưởng, được bảo vệ mà một quốc gia dành cho công dân của mình thông qua những thừa nhận và bảo đảm thực thi bởi pháp luật quốc gia $[6,649]$. Như vậy, khác với quyền con người được thừa nhận trên bình diện quốc tế, quyền công dân được thừa nhận và bảo đảm thực thi ở góc độ quốc gia, và là cách thức mà mỗi quốc gia đối xử với công dân của nước mình, tùy theo thể chế, chế độ chính trị mà quyền này được ghi nhận và bảo đảm thực hiện ở các mức độ khác nhau. Quyền của công dân được thừa nhận trong Hiến pháp của một quốc gia bao gồm các quyền cơ bản như: quyền về chính trị, kinh tế, xã hội, văn hóa, giáo dục và các quyền tự do cá nhân [7].

1.2. Thu viện với việc bảo đảm quyền con người, quyền công dân 
i) Khái niệm thư viện

Thư viện là thiết chế đã xuất hiện trên thế giới từ lâu đời, gắn với lịch sử phát triển, tiến bộ của nhân loại. Tại nhiều quốc gia trên thế giới, thư viện là biểu tượng của nền học vấn, tri thức của một dân tộc; là nơi lưu giữ những di sản thành văn, tri thức khoa học, giá trị văn hóa của một đất nước.

Thư viện là một thiết chế văn hóa-thông tin, có bộ sưu tập tài liệu được thu thập, xử lý, tổ chức, lưu giữ, bảo quản bởi các chuyên gia thông tin thư viện theo tiêu chuẩn về chuyên môn, nghiệp vụ thư viện, để tạo lập, cung cấp thông tin, sản phẩm và dịch vụ thông tin thư viện đáp ứng quyền tiếp cận thông tin và hưởng thụ các giá trị văn hóa, phục vụ học tập, nghiên cứu, giải trí và các nhu cầu về thông tin khác của mỗi cá nhân, tổ chức.

Từ định nghĩa này, có thể nhận diện:

1) Thư viện là một thiết chế văn hóa - thông tin của xã hội. Thiết chế này giữ vai trò quan trọng trong việc lưu giữ, bảo tồn, phát triển các giá trị văn hóa trong toàn xã hội, truyền bá thông tin, tri thức, phục vụ các nhu cầu khác nhau trong xã hội.

2) Thư viện mang chức năng văn hóa, chức năng thông tin và chức năng giáo dục và chức năng giải trí, trong đó nhấn mạnh thư viện là một trong những công cụ của Nhà nước nhằm bảo đảm quyền tiếp cận thông tin và hưởng thụ các giá trị văn hóa, tham gia vào hoạt động văn hóa, sử dụng các thiết chế văn hóa của người dân.

ii) Vai trò của thư viện trong việc bảo đảm quyền con người, quyền công dân

Từ việc nhận diện bản chất của thư viện, có thể thấy, thư viện là một thiết chế quan trọng của một quốc gia, giữ vai trò trong việc bảo đảm quyền tiếp cận thông tin, quyền hưởng thụ các giá trị văn hóa, tham gia vào đời sống văn hóa và sử dụng các thiết chế văn hóa. Những quyền này nhằm thúc đẩy việc học tập, nâng cao trình độ, tri thức, phát triển đời sống văn hóa tinh thần của người dân, thúc đẩy việc xây dựng văn hóa, con người đáp ứng yêu cầu phát triển bền vững đất nước. Như vậy, 02 quyền con người, quyền công dân được mỗi quốc gia thừa nhận mà thư viện là công cụ để bảo đảm thực thi đó là:

- Quyền tiếp cận thông tin (Điều 69 Hiến pháp 1992 gọi là "quyền được thông tin", Hiến pháp 2013 gọi là "quyền tiếp cận thông tin"); trong nghiên cứu này, quyền tiếp cận thông tin được hiểu là: quyền công dân được tạo ra thông tin, tìm kiếm, tiếp nhận, phổ biến, trao đổi và sủ dưng thông tin; quyền được sư dung các sản phẩm và dịch vu tù các thiết chế cung cấp thông tin trên nguyên tắc tư do, bình đẳng trong tiếp cận [11 - 13]. Quyền tiếp cận thông tin trong nghiên cứu này được hiểu theo nghĩa rộng, theo đó, chủ thể tham gia trong quan hệ pháp luật về tiếp cận thông tin không chỉ bao gồm giữa công dân với cơ quan nhà nước, mà còn giữa công dân với các thiết chế cung cấp thông tin (đó là các thư viện), trong đó Nhà nước giữ vai trò điều tiết, tạo hành lang pháp lý để bảo đảm quyền tiếp cận thông tin thông qua các chế định của pháp luật về tiếp cận thông tin.

- Quyền hưởng thụ các giá trị văn hóa, tham gia vào đời sống văn hóa và sử dụng các thiết chế văn hóa được đề cập tại Điều 41 Hiến pháp 2013; trên bình diện quốc tế, Điều 27 của Tuyên ngôn Quốc tế về nhân quyền có khẳng định: moi người có quyền tụ do tham gia vào đờ sống văn hóa của cộng đồng, được thuởng thức nghệ thuật và chia sẻ những tiến bộ khoa hoc cũng nhu nhũng lợi ich xuất phát tù nhũng tiến bộ khoa học. Trong Điều 15 Công ước Quốc tế về các Quyền kinh tế, xã hội và văn hóa đã cụ thể hóa Điều 27 bao gồm các quyền: a) được tham gia vào đời sống văn hóa; b) được huơơng các lợi ich của tiến bộ khoa hoc và úng dụng của nó; c) Đuợc bảo hộ các quyền lợi tinh thần và vật chất phát sinh tù bất kỳ sáng tạo khoa học, văn hoc, nghệ thuật nào của mình [8 - 9].

Thư viện là một trong những thiết chế bảo đảm các quyền cơ bản nêu trên thông qua việc thực hiện các chức năng của mình đó là: chức năng thông tin, chức năng văn hóa, chức năng giáo dục và chức năng giải trí. Trong Tuyên ngôn của UNESCO về thư viện công cộng đã khẳng định "Thu viện công cộng mở ra sư tiếp cận tới tri thức ở cơ sỏ̉, bảo đảm khả năng chủ yếu cho việc học tập liên tục cho việc tụ minh 
đưa ra quyết định và cho sụ phát triển văn hóa của cá nhân và các nhóm xã hội. Tuyên ngôn này bày tỏ niềm tin của UNESCO vào thu viện công công nhu là lục luợng tích cực tác động đến việc phổ cập giáo dục, văn hóa và thông tin, cũng là yếu tố quan trọng nhất giúp củng cố hòa bình và cuộc sống tinh thần trong tâm trí của nam giới và nũ gió́t" [10].

Thực tiễn ở Việt Nam hiện nay, mạng lưới thư viện phát triển rộng khắp với nhiều loại hình thư viện trong đó, hệ thống thư viện công cộng bao gồm: Thư viện Quốc gia Việt Nam, 63 thư viện cấp tỉnh, 665 thư viện cấp huyện, 2.970 thư viện cấp xã và gần 17.385 phòng đọc, tủ sách cơ sở; Mạng lưới thư viện chuyên ngành cũng có sự phát triển với 400 thư viện các trường đại học, cao đẳng, học viện; 25.915 thư viện các trường phổ thông, trên 100 thư viện chuyên ngành trong các cơ quan nhà nước, thư viện lực lượng vũ trang) ${ }^{1}$, ngoài ra còn có các thư viện tư nhân có phục vụ cộng đồng. Sự phát triển của thư viện trong suốt thời gia qua đã góp phần đắc lực trong công cuộc nâng cao dân trí, bồi dưỡng nhân tài và phát triển văn hóa đọc trong cộng đồng trên nguyên tắc bình đẳng trong tiếp cận thông tin, tri thức.

iii) Chế định pháp luật về quyền con người, quyền công dân trong Luật Thư viện

Theo từ điển pháp luật, Chế định pháp luật là tổng thể các quy phạm pháp luật điều chỉnh các nhóm quan hệ xã hội gần gũi, có cùng tính chất $[6$, tr259]. Như vậy, chế định pháp luật về bảo đảm quyền con người, quyền công dân trong Luật Thư viện là tổng thể các quy phạm pháp luật điều chỉnh các quan hệ liên quan đến quyền con người, quyền công dân bao gồm: Quyền tiếp cận thông tin, quyền hưởng thụ các giá trị văn hóa, quyền tham gia vào đời sống văn hóa và sử dụng các thiết chế văn hóa được đề cập trong Luật Thư viện và những biện pháp bảo đảm thực hiện các quyền này.

\footnotetext{
${ }^{1}$ Nguồn: Số liệu được nêu tại Báo cáo đánh giá tác động các chính sách được nêu tại Dự án Luật Thư viện do Bộ Văn hóa, Thể thao và Du lịch xây dựng.
}

\section{Tổng quan về những chế định Pháp luật về quyền con người và quyền công dân được đề cập trong Luật Thư viện}

2.1. Nội dung quyền tiếp cận thông tin, tiếp cận
và hướng thu các giá trị văn hóa, tham gia vào
đời sống văn hóa, sử dụng các thiết chế văn hóa

i) Quyền tiếp cận thông tin, tiếp cận và hưởng thụ các giá trị văn hóa và sử dụng cơ sở văn hóa

Luật Thư viện đã cụ thể hóa quyền tiếp cận thông tin, hưởng thụ các giá trị văn hóa và sử dụng các thiết chế văn hóa thông qua các quy định tại các Điều 42,43, 44 của Luật Thư viện, theo đó, người sử dụng thư viện (bao gồm cả tổ chức và cá nhân) có các quyền:

- Được sử dụng thư viện, tiếp cận và sử dụng tài nguyên thông tin và tiện ích thư viện phù hợp với nội quy thư viện, pháp luật về sở hữu trí tuệ, bảo vệ bí mật nhà nước và quy định pháp luật khác có liên quan.

- Được miễn phí tại thư viện công lập đối với các hoạt động: Sử dụng tài nguyên thông tin tại thư viện, mượn theo thời hạn quy định định trong nội quy của thư viện; Tra cứu thông tin trên không gian mạng; tiếp nhận thông tin về tài nguyên thông tin qua hệ thống tra cứu hoặc hình thức tiếp nhận thông tin, tra cứu khác; Được giúp đỡ, tư vấn về tìm kiếm, lựa chọn tài nguyên thông tin phù hợp với yêu cầu; Các hoạt động khác theo quy định.

Ngoài ra người sử dụng thư viện còn có các quyền: được sử dụng dịch vụ thư viện theo danh mục dịch vụ do thư viện cung cấp; được hướng dẫn sử dụng thư viện, hỗ trợ trang bị kỹ năng tìm kiếm, khai thác và sử dụng thông tin; được tham gia các hoạt động dành cho người sử dụng thư viện do thư viện tổ chức; được lựa chọn thư viện phù hợp với nhu cầu và quy chế, nội quy thư viện; được khiếu nại, tố cáo về hành vi hạn chế quyền sử dụng thư viện.

Đối với những nhóm đặc thù, những đối tượng yếu thế trong xã hội, Luật Thư viện cũng có những quy định quan trọng nhằm bảo đảm việc thực hiện quyền con người, quyền công dân, một cách bình đẳng với các chủ thể khác 
trong xã hội, theo đó, Điều 44 của Luật Thư viện quy định:

Người dân tộc thiểu số được tạo điều kiện sử dụng tài nguyên thông tin bằng tiếng nói, chữ viết của dân tộc mình phù hợp với điều kiện của thư viện.

Người sử dụng thư viện là người cao tuổi hoặc người khuyết tật mà không thể tới thư viện được tạo điều kiện sử dụng tài nguyên thông tin tại nhà thông qua dịch vụ thư viện lưu động hoặc gửi qua bưu chính, không gian mạng khi có yêu cầu phù hợp với hoạt động của thư viện.

Người khiếm thị, người khiếm thính có quyền sử dụng tài nguyên thông tin theo quy định và được tạo điều kiện sử dụng tài liệu in chữ nổi Braille, tài liệu nghe, nhìn, tài liệu ngôn ngữ ký hiệu hoặc tài liệu đặc biệt khác.

Trẻ em được tạo điều kiện sử dụng tài nguyên thông tin phù hợp với lứa tuổi, cấp học tại thưu viện cơ sở giáo dục và thư viện công cộng.

Trẻ em, người cao tuổi, thương binh, người khuyết tật, người thuộc hộ nghèo, hộ cận nghèo được miê̂n các khoản chi phí làm thẻ thư viện.

Người đang chấp hành hình phạt tù, học tập, cải tạo tại trại giam, cơ sở giáo dục bắt buộc, trường giáo dưỡng, cơ sở cai nghiện bắt buộc được tạo điều kiện sử dụng tài nguyên thông tin của thư viện tại nơi giam giữ, học tập và chữa bệnh.

Tổng quan các quy định nêu trên, có thể nhận diện, Luật Thư viện đã bao phủ và đề cập hầu hết các nội dung trong việc bảo đảm việc tiếp cận thông tin, tiếp cận các giá trị văn hóa, hưởng thụ các giá trị văn hóa và sử dụng cơ sở văn hóa (sử dụng thư viện) đối với mọi đối tượng trong xã hội bao gồm cả những đối tượng đặc thù trong xã hội như: những người chấp hành hình phạt tù, học tập, cải tạo tại trại giam, đây là những đối tượng bị cách ly khỏi xã hội, mất một phần hoặc toàn bộ quyền công dân, song vần còn quyền con người; thông qua tiếp cận các giá trị văn hóa từ sách, báo và tri thức giúp họ sớm hoàn lương. Các đối tượng yếu thế trong xã hội như người khiếm thị, người khuyết tật, trẻ em, người cao tuổi.. cũng được bảo đảm việc tiếp cận thông tin một cách tối đa thông qua các quy định có tính đặc thù, đáp ứng với việc tiếp cận và sử dụng thư viện phù hợp với điều kiện, hoàn cảnh, lứa tuổi của họ. Đặc biệt, nâng cao mức hưởng thụ các giá trị văn hóa cho đồng bào dân tộc thiểu số, Luật Thư viện cũng đã có quy định có liên quan đến việc bảo đảm cho việc người dân tộc thiểu số có thể tiếp cận với ngôn ngữ và chữ viết của dân tộc mình trong thư viện.

Đi cùng với việc xác định những quyền con người, quyền công dân, Luật Thư viện đã xác định những gianh giới, trong việc thực hiện các quyền này nhằm bảo đảm việc thực thi nó một cách hiệu quả. Điều 7 của Luật đã quy định về tài nguyên thông tin hạn chế sử dụng trong thư viện, nhằm giới hạn việc tiếp cận thông tin bao gồm:

- Tài nguyên thông tin có nội dung nếu sử dụng rộng rãi có thể ảnh hưởng đến lợi ích của Nhà nước, quyền và lợi ích hợp pháp của tổ chức, cá nhân;

- Tài nguyên thông tin thuộc bí mật nhà nước, hạn chế sử dụng, tiếp cận có điều kiện, hạn chế quyền tiếp cận theo quy định của pháp luật về bảo vệ bí mật nhà nước, tiếp cận thông tin và lưu trữ;

- Bản gốc tài liệu cổ, quý hiếm, tài nguyên thông tin là di sản văn hóa đang lưu giữ trong thư viện;

- Bản gốc tài liệu bị hư hỏng.

Như vậy, Luật Thư viện đã "khoanh vùng" những nguồn thông tin mà công dân hạn chế tiếp cận, với các quy định về hạn chế trong nội dung thông tin và hình thức thể hiện của thông tin. Đặc biệt đối với các dạng thông tin hạn chế sử dụng theo quy định tại điểm a khoản 1 Điều 7, Luật đã quy định các thư viện được lưu giữ để phục vụ cho hoạt động nghiên cứu (khoản 10 Điều 38 Luật Thư viện) nhằm bảo đảm cho việc phát huy một cách tối đa giá trị của các thông tin này, bảo đảm cho mọi đối tượng có thể tiếp cận và sử dụng sách, báo và các giá trị của thư viện phục vụ học tập, nghiên cứu và hưởng thụ các giá trị văn hóa.

ii) Quyền tham gia vào hoạt động văn hóa

Luật Thư viện đã cụ thể hóa quyền của con người, quyền của công dân trong việc tham gia vào hoạt động văn hóa được quy định tại Hiến pháp. Thông qua các quy định này, người dân trở thành trung tâm và là chủ thể chính tham gia 
vào hoạt động văn hóa với tư cách là đối tượng hưởng thụ các giá trị hoặc với tư cách là đối tượng tạo ra các giá trị văn hóa.

Khi tham gia vào hoạt động văn hóa với tư cách là đối tượng hưởng thụ văn hóa, người dân có các quyền đã được phân tích ở mục a; tại mục này chủ yếu tập trung phân tích, nhận diện các quyền của người dân với tư cách là đối tượng tạo ra các giá trị văn hóa trong thư viện thông qua việc thành lập thư viện và tham gia các hoạt động thư viện.Theo đó, Điều 20 Luật Thư viện đã quy định về quyền thành lập thư viện ngoài công lập khi đáp ứng đủ các điều kiện theo quy định của Luật. Ngoài ra, bằng việc đa dạng hóa các loại hình thư viện, Luật Thư viện đã có các quy định tạo điều kiện để tổ chức, cá nhân có thể thành lập thư viện theo mô hình doanh nghiệp nhằm tạo ra lợi nhuận, cung ứng các sản phẩm và dịch vụ văn hóa, thông tin tốt hơn. Từ đây có thể thấy, Luật Thư viện đã phần nào cụ thể hóa quyền tự do kinh doanh, tham gia vào các hoạt động văn hóa-thông tin của tồ chức cá nhân, đồng thời góp phần hoàn thiện các chính sách của nhà nước trong xã hội hóa hoạt động văn hóa.

Để cụ thể hóa quyền của tổ chức, cá nhân trong tham gia hoạt động thư viện với từ cách là chủ thể thành lập thư viện, Điều 38 của Luật Thư viện đã quy định các quyền của Thư viện bao gồm: 1) xác định nội dung và hình thức hoạt động phù hợp với chức năng, nhiệm vụ của thư viện; 2 ) trao đổi tài nguyên thông tin, tham gia vào hệ thống thư viện trong nước và nước ngoài theo quy định của pháp luật; 3 ) từ chối yêu cầu sử dụng tài nguyên thông tin trái với quy định của pháp luật, quy chế, nội quy thư viện; 4) thu phí, giá từ việc cung cấp dịch vụ thư viện theo quy định của pháp luật; 5) nghiên cứu, ứng dụng thành tựu khoa học và công nghệ tiên tiến, thiết lập cơ sở hạ tầng kỹ thuật, đáp ứng yêu cầu hiện đại hóa thư viện; 6) vận động, tiếp nhận tài trợ, viện trợ, tặng, cho, đóng góp cho thư viện theo quy định của pháp luật; 7) mở rộng phục vụ đối tượng người sử dụng thư viện phù hợp với quy định của pháp luật và quy chế thư viện; 8 ) Hợp tác quốc tế về thư viện; 9) xác định hình thức và giá trị bồi thường thiệt hại do người sử dụng thư viện cây ra theo quy định của pháp luật và nội quy thư viện.

Tổ chức cá nhân tham gia hoạt động thư viện với tư cách là người làm công tác thư viện, Điều 40 của Luật Thư viện đã quy định các quyền cơ bản như: 1) được học tập, bồi dưỡng, nâng cao trình độ chuyên môn, nghiệp vụ, kiến thức quản lý thư viện và kỹ năng sử dụng trang thiết bị, phương tiện kỹ thuật hiện đại ứng dụng trong hoạt động thư viện, 2) được tham gia nghiên cứu khoa học, sinh hoạt chuyên môn, nghiệp vụ; tham gia tổ chức xã hội nghề nghiệp về thư viện; 3 ) được hưởng lương; chế độ, chính sách ưu đãi nghề nghiệp theo quy định của pháp luật.

Như vậy thông qua quy định về quyền của tổ chức cá nhân tham gia hoạt động thư viện trong Luật thư viện, các chế định về quyền tiếp cận thông tin, quyền được hưởng thụ các giá trị văn hóa, tham gia vào đời sống văn hóa và sử dụng cơ sở văn hóa đã được cụ thể hóa, tạo cơ sở pháp lý quan trọng trong việc thúc đẩy việc nâng cao dân trí, năng lực thông tin, khả năng tiếp cận và hưởng thụ các giá trị văn hóa của người dân thông qua tham gia vào hoạt động thư viện.

\subsection{Các biện pháp thực thi quyền tiếp cận} thông tin, tiếp cận và huơong thụ các giá trị văn hóa, tham gia vào đời sống văn hóa, sủ dụng các thiết chế văn hóa

Để bảo đảm cho việc thực thi quyền tiếp cận thông tin, tiếp cận và hưởng thụ các giá trị văn hóa, tham gia vào đời sống văn hóa, sử dụng các thiết chế văn hóa, Luật Thư viện đã có những quy định tạo hành lang pháp lý trong việc thực hiện các quyền con người, quyền công dân được quy định tại Hiến pháp, cụ thể:

i) Quy định về chính sách của Nhà nước trong phát triển sự nghiệp thư viện

Luật Thư viện đã cụ thể hóa các chính sách của Nhà nước trong phát triển sự nghiệp thư viện nhằm nâng cao năng lực cung ứng các sản phẩm và dịch vụ thông tin thư viện, phục vụ nhu cầu tiếp cận thông tin, tiếp cận và hưởng thụ các giá trị văn hóa của người dân. Chính sách của Nhà nước trong phát triển sự nghiệp 
thư viện được quy định tại Điều 5 của Luật Thư viện bao gồm các nội dung cơ bản như: i) Đầu tư cho thư viện công lập với các nội dung: Uu tiên đầu tư cho Thư viện Quốc gia Việt Nam, Thư viện công cộng tỉnh, thành phố trực thuộc trung ương và thư viện có vai trò quan trọng; hiện đại hóa thư viện; xây dựng thư viện số, tài nguyên thông tin dùng chung, tài nguyên thông tin mở; liên thông thư viện trong nước và nước ngoài; sưu tầm, bảo quản và phát huy giá trị tài liệu cồ quý hiếm, các bộ sưu tập tài liệu đặc biệt có giá trị về lịch sử, văn hóa, khoa học; tổ chức dịch vụ thư viện lưu động, luân chuyển tài nguyên thông tin phục vụ khu vực biên giới, hải đảo, vùng đồng bào dân tộc thiểu số, vùng có điều kiện kinh tế-xã hội khó khăn, đặc biệt khó khăn; đào tạo, bồi dưỡng, nâng cao năng lực phát triển nguồn nhân lực thư viện; nghiên cứu, ứng dụng thành tựu khoa học và công nghệ tiên tiến trong hoạt động thư viện. ii) Nhà nước hỗ trợ đầu tư các nội dung: cung cấp các dịch vụ sự nghiệp công trong lĩnh vực thư viện, phát triển văn hóa đọc; duy trì và phát triển cộng đồng, thư viện tư nhân có phục vụ cộng đồng không vì mục tiêu lợi nhuận và cước vận chuyển tài liệu thư viện phục vụ nhiệm vụ chính trị, khu vực biên giới, hải đảo, vùng có điều kiện khó khăn, đặc biệt khó khăn.

Đi cùng với đó, Nhà nước cũng có các chính sách khuyến khích tổ chức, cá nhân tham gia hoạt động thư viện với tư cách là chủ thể thành lập thư viện thông qua chính sách xã hội hóa trong hoạt động thư viện, theo đó, tại Điều 6 của Luật quy định (1) cộng đồng dân cư, tổ chức, cá nhân được tạo điều kiện để đầu tư, tài trợ, viện trợ, tặng, cho, đóng góp phát triển sự nghiệp thư viện, văn hóa đọc, xây dựng và phát huy không gian đọc. (2) Cộng đồng dân cư, tổ chức, cá nhân tham gia hoạt động thư viện được hưởng ưu đãi theo quy định của pháp luật; (3) cộng đồng dân cư, tổ chức, cá nhân đầu tư xây dựng cơ sở vật chất, trang thiết bị cho thư viện; tài trợ, viện trợ, tặng, cho, đóng góp để phát triển sự nghiệp thư viện và phát triển văn hóa đọc được ghi nhận và vinh danh theo quy định của pháp luật về thi đua khen thưởng.

Các chính sách này đều nhằm hướng tới việc tăng cường tiềm lực cho hoạt động thư viện, bảo đảm thực hiện các quyền của tổ chức, cá nhân trong hoạt động thư viện với vai trò là chủ thể tham gia sử dụng thư viện, tham gia thành lập và hoạt động thư viện.

ii) Thiết lập mạng lưới thư viện

Luật Thư viện đã thiết lập một mạng lưới thư viện rộng khắp với đầy đủ các loại hình, mô hình hoạt động thư viện phù hợp với thông lệ quốc tế trong phân chia các loại hình thư viện, từ đó tạo cơ hội cho người dân có thể tiếp cận đến thư viện, sử dụng và hưởng thụ các giá trị văn hóa-thông tin mà thư viện mang lại. Luật Thư viện đã xây dựng 08 loại hình cơ bản trong mạng lưới thư viện của quốc gia tương ứng với từng nhu cầu sử dụng thông tin của các nhóm đối tượng xã hội khác nhau bao gồm: Thư viện Quốc gia Việt Nam, Thư viện công cộng (Phục vụ cho mọi đối tượng người sử dụng); Thư viện chuyên ngành (phục vụ cho các đối tượng nghiên cứu chuyên biệt trong các cơ quan nhà nước, viện nghiên cứu..), thư viện lực lượng vũ trang nhân dân (Phục vụ cho các đối tượng trong lực lượng vũ trang nhân dân), thư viện trong cơ sở giáo dục đại học, thư viện trong cơ sở giáo dục mầm non, giáo dục phổ thông, giáo dục nghề nghiệp và các cơ sở giáo dục khác (phục vụ cho đối tượng trong các cơ sở giáo dục quốc dân).

Một trong những điểm mới so với Pháp lệnh Thư viện năm 2000, Luật Thư viện đã phân chia các loại hình này theo 02 nhóm đối tượng: thư viện công lập và thư viện ngoài công lập, trong thư viện ngoài công lập có các loại hình như: thư viện thư viện tư nhân có phục vụ công đồng, thư viện cộng đồng và thư viện của tổ chức, cá nhân nước ngoài có phục vụ người Việt Nam. Việc mở rộng phạm vi điều chỉnh của Luật Thư viện mang một ý nghĩa cực kỳ quan trọng không chỉ đối với vấn đề quản lý nhà nước về thư viện, mà nó còn tạo hành lang pháp lý trong việc thúc đẩy người dân tham gia hoạt động thư viện với tư cách là chủ thể thành lập thư viện; khuyến khích việc hội nhập quốc tế trong hoạt động thư viện. Từ sự mở rộng này, tạo cơ hội cho người dân có thêm nhiều lựa chọn trong việc thực hiện các quyền con người, quyền công dân, tạo ra sự liên kết, hỗ trợ giữa 
các loại thư viện trong phục vụ người dân tiếp cận và sử dụng thư viện.

Cùng với việc xác định các loại hình thư viện trong hệ thống thư viện quốc gia, Luật Thư viện đã xác định vị trí, vai trò và nhiệm vụ của mồi thư viện trong mạng lưới thư viện quốc gia, tương ứng với từng loại hình thư viện được quy định từ Điều 10 đến Điều 17 của Luật Thư viện với các loại hình: Thư viện Quốc gia Việt Nam (Điều 10), Thư viện Công cộng (Điều 11), Thư viện chuyên ngành (Điều 12), Thư viện lực lượng vũ trang nhân dân (Điều 13), Thư viện Đại học (Điều 14), Thư viện cơ sở giáo dục mầm non, cơ sở giáo dục phổ thông, cơ sở giáo dục nghề nghiệp và cơ sở giáo dục khác (Điều 15), Thư viện cộng đồng và thư viện tư nhân có phục vụ cộng đồng (Điều 16) và Thư viện của tổ chức, cá nhân nước ngoài có phục vụ người Việt Nam (Điều 17) từ đó tạo ra những trật tự nhất định thông qua việc phân công vai trò, trách nhiệm của từng loại hình thư viện trong việc bảo đảm cho người dân có thể tiếp cận với thông tin, tri thức. phục vụ phát triển văn hóa.

Việc thiết lập mạng lưới thư viện còn gắn với việc xác định điều kiện thành lập và thẩm quyền thành lập các loại thư viện. Theo đó, Điều 18 của Luật Thư viện đã xác định thư viện được thành lập khi đáp ứng các điều kiện về: mục tiêu, đối tượng phục vụ; tài nguyên thông tin phù hợp với chức năng, nhiệm vụ, đối tượng phục vụ của thư viện; cơ sở vật chất, trang thiết bị bảo đảm phục vụ hoạt động thư viện; người làm công tác thư viện có chuyên môn, nghiệp vụ phù hợp với hoạt động thư viện; người đại diện theo pháp luật của thư viện có năng lực hành vi dân sự đầy đủ. Việc xác định điều kiện thành lập thư viện mang một ý nghĩa quan trọng trong việc tạo điều kiện cho người dân có thể tham gia vào hoạt động văn hóa với tư cách là chủ thể thành lập thư viện. Các quy định về thành lập thư viện được xây dựng trên tinh thần đơn giản hóa thủ tục hành chính, tạo điều kiện để các chủ thể khác nhau tham gia thành lập hoạt động thư viện.

iii) Chuẩn hóa hoạt động thư viện

Hoạt động thư viện được xem là một trong những phương tiện quan trọng để bảo đảm các quyền con người, quyền của công dân trong hoạt động của thư viện. Trong toàn bộ kết cấu của Luật Thư viện, hoạt động thư viện chiếm một số lượng nhiều nhất (bao gồm 14 điều) từ Điều 24 đến Điều 37 với các quy định nhằm chuẩn hóa hoạt động thư viện, thiết lập các cơ chế vận hành trong hoạt động thư viện, thúc đẩy hoạt động thư viện không ngừng đổi mới, sáng tạo trong hoạt động để nâng cao năng lực cung ứng thông tin, sản phẩm và dịch vụ thư viện nhằm bảo đảm quyền tiếp cận thông tin, tiếp cận và hưởng thụ các giá trị văn hóa của người dân trong bối cảnh phát triển của khoa học và công nghệ. Các quy định về chuẩn hóa hoạt động thư viện được xem là những quy định mới so với Pháp lệnh Thư viện năm 2000.

Việc chuẩn hóa hoạt động thư viện được xây dựng trên nền tảng nguyên tắc cơ bản được quy định tại Điều 24 của Luật với các quy định: 1) lấy người sử dụng thư viện làm trung tâm; tạo lập môi trường thân thiện, bình đẳng; bảo đảm quyền tiếp cận và sử dụng thư viện của tổ chức, cá nhân; 2) tài nguyên thông tin được thu thập xử lý, lưu giữ, bảo quản và phổ biến tuân thủ tiêu chuẩn, quy chuẩn kỹ thuật quốc gia và chuẩn nghiệp vụ trong lĩnh vực thư viện; 3) thường xuyên đổi mới sáng tạo về quy trình, sản phẩm thông tin, dịch vụ thư viện trên cơ sở ứng dụng thành tựu khoa học và công nghệ tiên tiến; 4) Thực hiện liên thông thư viện; 5) Tuân thủ quy định của pháp luật về sở hữu trí tuệ, khoa học và công nghệ, công nghệ thông tin và các quy định khác của pháp luật có liên quan. Đây là 05 nguyên tắc xuyên suốt trong từng hoạt động của thư viện thúc đẩy sự chuẩn hóa trong hoạt động của thư viện. Trong đó,việc lấy người sử dụng làm trung tâm, tạo lập môi trường bình đẳng, thân thiện là một trong những nguyên tắc mang tính triết lý nhằm hướng hoạt động thư viện trong việc thực hiện quyền con người, quyền công dân. Các nguyên tắc còn lại thúc đẩy quá trình chuẩn hóa trong hoạt động thư viện, để hoạt động này góp phần thực thi các quyền cơ bản này trong bối cảnh phát triển của khoa học và công nghệ tác động đến phương thức tiếp cận, hưởng thụ các giá trị 
văn hóa, tiếp cận đến các cơ sở văn hóa của người dân.

Luật Thư viện đã quy phạm hóa các hoạt động chuyên môn quan trọng của thư viện nhằm tiến đến chuẩn hóa hoạt động thư viện như: Xây dựng tài nguyên thông tin, xử lsy tài nguyên thông tin và tổ chức hệ thống tra cứu thông tin; bảo quản tài nguyên thông tin; tạo lập cung cấp sản phẩm thông tin thư viện và dịch vụ thư viện; truyền thông thư viện và đánh giá hoạt động thư viện. Đây là những nội dung cơ bản mà mỗi thư viện cần triển khai để phục vụ người sử dụng. Ngoài ra Luật Thư viện cũng đã quy định những hoạt động có tính chất bổ trợ cho hoạt động thư viện như vân đề hiện đại hóa thư viện, nguồn tài chính cho hoạt động thư viện, hợp tác quốc tế về thư viện.. nhằm giúp thư viện khẳng định vị trí, vị thế của mình trong việc bảo đảm quyền tiếp cận thông tin, tiếp cận và hưởng thụ các giá trị văn hóa đối với người dân.

Đặc biệt, để thúc đẩy phát triển văn hóa nói chung, và văn hóa đọc của cộng đồng nói riêng, Luật Thư viện đã quy định 01 điều về phát triển văn hóa đọc (Điều 30), theo đó, ngày 21 tháng 4 hằng năm là ngày Sách và Văn hóa đọc Việt Nam. Đồng thời có các quy định về phát triển văn hóa đọc thông qua các hoạt động: tổ chức hoạt động hình thành thói quen đọc trong gia đình, trường học, cơ quan, tổ chức trong phạm vi cả nước; hướng dẫn phương pháp, kỹ năng đọc, khai thác tài nguyên thông tin cho trẻ em tại thư viện cơ sở giáo dục mầm non, thư viện cơ sở giáo dục phổ thông; phát triển kỹ năng tìm kiểm, khai thác và sử dụng thông tin, mở rộng tri thức cho người sử dụng thư viện; đẩy mạnh liên thông giữa thư viện công cộng với các thư viện khác trên địa bàn; truy cập và khai thác thông tin, tri thức từ thư viện số dùng chung thông qua thiết bị điệu tử; sử dụng dịch vụ thư viện lưu động và luân chuyển tài nguyên thông tin. Quy định này nhằm thúc đẩy thư viện thường xuyên tổ chức các hoạt động văn hóa, tạo cơ hội cho người dân tiếp cận và hưởng thụ các giá trị văn hóa, tạo động lực phát triển văn hóa đọc trong cộng đồng.

iv) Các chế định về nghĩa vụ trong hoạt động của thư viện
Quyền con người, quyền công dân sẽ tương ứng với nghĩa vụ của Nhà nước trong bảo đảm thực thi các quyền này, Nhà nước thực hiện nghĩa vụ này thông qua các quy định về nghĩa vụ, trách nhiệm của thư viện và các chủ thế có liên quan trong việc bảo đảm quyền tiếp cận thông tin, tiếp cận và hưởng thụ các giá trị văn hóa, tham gia vào đời sống văn hóa và sử dụng các cơ sở văn hóa của người dân trên các khía cạnh khác nhau của lĩnh vực thư viện. Luật Thư viện đã quy định 02 điều về trách nhiệm của thư viện (Điều 39) và nghĩa vụ của người làm công tác thư viện (Điều 41) để cụ thể hóa các nội dung này, theo đó:

Thư viện có trách nhiệm bảo đảm thực hiện quyền tiếp cận thông tin và sử dụng dịch vụ thư viện; tổ chức dịch vụ thư viện, bố trí thời gian phục vụ phù hợp với điều kiện sinh hoạt, làm việc, học tập của ngưới sử dụng thư viện, công bố nội quy, hướng dẫn sử dụng thư viện, công khai minh bạch về tài nguyên thông tin và hoạt động thư viện. Ngoài ra, việc nâng cao chất lượng hoạt động thư viện hông qua việc tổ chức hoạt động chuyên môn, nghiệp vụ thư viện theo quy định và hoạt động khác phù hợp với chức năng nhiệm vụ của thư viện cũng là một trong những nội dung cơ bản trong trách nhiệm của thư viện. Các quy định về trách nhiệm của thư viện đều hướng tới 02 yếu tố: đó là tạo thuận lợi cho người dân có thể dễ dàng tiếp cận với thư viện và tạo động lực để nâng cao chất lượng hoạt động thư viện.

Đối với người làm công tác thư viện, một trong những nghĩa vụ quan trọng về bảo đảm quyền tiếp cận thông tin được Luật quy định đó là: tạo điều kiện để người sử dụng thư viện tiếp cận, sử dụng tài nguyên thông tin và tiện ích thư viện; bảo đảm quyền bình đẳng và các quyền khác của người sử dụng thư viện được quy định tại Luật này; hỗ trợ, trang bị kỹ năng tìm kiếm, khai hác và sử dụng thông tin cho người sử dụng thư viện, đây là những biện pháp bảo đảm thực thi quan trọng được nêu tại Luật Thư viện.

Ngoài ra, Luật Thư viện đã đề cao và bổ sung trách nhiệm của cơ quan, tổ chức, cá nhân trong thành lập, quản lý và có liên quan đến 
hoạt động thư viện nhằm bảo đảm các nguồn lực cho thư viện hiệu quả, tạo điều kiện để người dân trở thành chủ thể chính tham gia vào hoạt động thư viện theo quy định của pháp luật. Điều 45 của Luật Thư viện quy định về trách nhiệm của cơ quan, tổ chức, cá nhân thành lập với các trách nhiệm khác nhau nhằm bảo đảm cơ chế vận hành cho của thư viện: như liên quan đến bảo đảm nguồn lực như: nguồn nhân lực, cơ sở vật chất bảo đảm điều kiện về phòng cháy chữa cháy, bảo vệ môi trường và phòng chống thiên tai; ban hành các quy chế hoạt động, thực hiện chế độ chính sách, ưu đãi nghề nghiệp cho người làm công tác thư viện và những trách nhiệm đặc thù tương ứng với từng loại hình thư viện.

Điều 46 của Luật Thư viện quy định về trách nhiệm của cơ quan, tổ chức, cá nhân trực tiếp quản lý thư viện với 05 trách nhiệm gắn với việc xây dựng, tổ chức thực hiện kế hoạch hoạt động thư viện, phát triển tài nguyên thông tin và phát triển văn hóa đọc; sử dụng hiệu quả nguồn lực đầu tư cho thư viện; tạo điều kiện cho người làm công tác thư viện được bồi dưỡng, nâng cao trình độ chuyên môn, nghiệp vụ của thư viện và các nhiệm vụ chuyên môn, nghiệp vụ khác có liên quan.

Điều 47 của Luật Thư viện quy định trách nhiệm của các chủ thể khác nhau trong xã hội trong việc phát triển hoạt động thư viện, trong đó đề cao trách nhiệm của các chủ thể như: cơ quan, tổ chức xuất bản, báo chí, người bảo vệ luận án tiến sĩ ở trong nước, nước ngoài; công dân nước ngoài bảo vệ luận án tiến sĩ ở Việt Nam; người dạy trong cơ sở giáo dục, tổ chức xã hội-nghề nghiệp về thư viện trong việc hỗ trợ các nguồn lực bảo đảm cho sự phát triển của thư viện.

Các chế định về nghĩa vụ này nhằm tạo điều kiện để mọi người có thể tham gia đóng góp công sức, tiền của, vật chất trong việc phát triển sự nghiệp thư viện đồng thời trở thành chủ thể chính với vị trí là trung tâm trong hoạt động thư viện.

\section{Kết luận và kiến nghị}

Thư viện là một trong những yếu tố bảo đảm công bằng, bình đẳng và lợi ích cho toàn thể mọi người trong xã hội trong việc tiếp cận thông tin, tiếp cận và hưởng thụ các giá trị văn hóa, tham gia vào đời sống văn hóa và sử dụng cơ sở văn hóa từ đó thúc đẩy việc học tập suốt đời, nâng cao trình độ, phát triển văn hóa đọc và các hoạt động giải trí phục vụ các nhu cầu khác nhau của mỗi cá nhân; nhiều học giả quốc tế cho rằng, thư viện là hiện thân của một xã hội xã hội chủ nghĩa hiện đại. Sự có mặt của Luật Thư viện đã bổ sung những chế định pháp lý hết sức quan trọng về quyền tiếp cận thông tin đối với những thông tin không hình thành và phát sinh trong hoạt động quản lý nhà nước của cơ quan công quyền, bảo đảm cho công dân có thể tiếp cận thông tin một cách bình đẳng để phục vụ cho lợi ích của mình; bổ sung các chế định pháp lý quan trọng về quyền được hưởng thụ các giá trị văn hóa, tham gia vào đời sống văn hóa và sử dụng các cơ sở văn hóa của người dân thông quá các quy định về quyền của người sử dụng thư viện, quyền của các đối tượng đặc thù, từ đó quy định những biện pháp bảo đảm các quyền này thông qua các quy định về chức năng, nhiệm vụ của từng loại hình thư viện, các nội dung trong hoạt động thư viện, các nghĩa vụ, trách nhiệm của tổ chức cá nhân liên quan trong hoạt động thư viện.

Để bảo đảm thực thi các chế định pháp luật về quyền con người, quyền công dân được nêu tại Luật Thư viện, xin đưa ra một số khuyến nghị như sau:

Một là, liên quan đến việc cụ thể hóa các nội dung được Luật Thư viện giao, các cơ quan, đơn vị có liên quan (Chính phủ, Bộ Văn hóa, Thể thao và $D u$ lịch) cần tiếp tục nghiên cứu sớm xây dựng và ban hành các văn bản hướng dẫn thi hành, nhằm cụ thể hóa các quy định của Luật, bảo đảm tính thực thi, hiệu lực hiệu quả trong thi hành Luật Thư viện.

Hai là, cơ quan chủ trì soạn thảo Luật Thư viện tăng cường tuyên truyền, phổ biến, giáo dục pháp luật về thư viện để tổ chức, cá nhân có thể 
nắm bắt đầy đủ các quy định về quyền, nghĩa vụ, trách nhiệm của mình khi tham gia các quan hệ pháp luật do Luật Thư viện điều chỉnh.

$B a$ là, hệ thống thư viện trong toàn quốc đẩy mạnh ứng dụng công nghệ thông tin, hiện đại hóa và thực hiện liên thông theo tinh thần của Luật Thư viện nhằm bảo đảm quyền tiếp cận thông tin, tiếp cận và hưởng thụ các giá trị văn hóa tại mọi thời điểm trong bối cảnh phát triển của khoa học và công nghệ. Đi kèm theo đó là trách nhiệm của tổ chức, các nhân liên quan trong việc bảo đảm các nguồn lực thúc đẩy việc đổi mới, chuẩn hóa hoạt động thư viện.

\section{Tài liệu tham khảo}

[1] Nguyễn Duy Quốc: Hiến pháp năm 2013 về quyền con người, quyền cơ bản của công dân, Tạp chí Nghiên cứu lập pháp số 12 (268), tháng 6 năm 2014.

[2] Uniterd Nations, Human Rights: Question and Anwers, Geneva, 1994, tr 4.

[3] OHCHR, Freequently Asked Question on a Human Rights-based Approach to Development Cooperation, New York and Geneva, 2006, tr 1.
[4] Phạm Khiêm Ích, Hoàng Văn Hảo (Chủ biên): Quyền con người trong thế giới hiện đại, Viện thông tin khoa học xã hội, Hà Nội 1995, tr19.

[5] Khoa Luật - Đại học Quốc gia Hà Nội, Giáo trình Lý luận và pháp luật về quyền con người, $\mathrm{NXB}$ Đại học Quốc gia Hà Nội, 2009, tr 38.

[6] Từ điển Luật học, NXB Tư pháp - NXB từ điển bách khoa.

[7] Vũ Công Giao, Nguyễn Minh Tâm ( 2015): Quyền công dân và cơ chế bảo vệ quyền công dân theo Hiến pháp năm 2013.

[8] Tuyên ngôn Thế giới về Quyền con người được Đại hội đồng Liên hiệp quốc thông qua tại Nghị quyết số 217 A (III) ngày 10/12/1948.

[9] Công ước quốc tế về các quyền dân sự và chính trị năm 1976.

[10] UNESCO, Tuyên ngôn năm 1994 của UNESCO về thư viện công cộng, Lê Văn Viết dịch theo bản tiếng Nga 1995 - số 6, tr6 (phụ chương).

[11] Nguyễn Đăng Dung (2016): Bình luận khoa học hiến pháp nước Cộng hòa xã hội chủ nghĩa Việt Nam năm 2013, NXB Chính trị Quốc gia.

[12] Học viện chính trị quốc gia. Trung tâm Nghiên cứu quyền con người. Các văn kiện thế giới về quyền con người, Sđd, $\operatorname{tr} 187$.

[13] Nguyễn Minh Thuyết (2016): Những vấn đề lý luận và thực tiễn về quyền tiếp cận thông tin ở nước ta hiện nay, Chương trình khoa học và công nghệ trọng điểm cấp Nhà nước KX.03/11-15. 